\title{
HUBUNGAN STATUS GIZI DAN UMUR MENARCHE DENGAN KEJADIAN DISMENORE PADA REMAJA PUTRI DI SMAN 2 BANGKINANG KOTA 2020
}

\author{
Syafriani $^{1}$, Nia Aprilla ${ }^{2}$, Zurrahmi Z. $\mathbf{R}^{3}$ \\ ${ }^{1}$ Program Studi Ilmu Kesehatan Masyarakat Universitas Pahlawan Tuanku Tambusai \\ ${ }^{2}$ Program Studi Sarjana Keperawatan Universitas Pahlawan Tuanku Tambusai \\ ${ }^{3}$ Program Studi D4 Bidan Pendidik Universitas Pahlawan Tuanku Tambusai \\ syafrianifani@gmail.com
}

\begin{abstract}
Abstrak
Rata-rata lebih dari 50\% perempuan mengalami kejadian dismenore, di Indonesia ada sebesar 72,89\%. Menurut WHO tahun 2013 angka kejadian dismenore 1. 769. 425 jiwa (90\%) wanita yang mengalami dismenore, terdapat $10-15 \%$ mengalami dismenore berat, rata-rata hampir dari $50 \%$ wanita mengalaminya. Faktor resiko penyebab dismenore pada saat menstruasi ialah umur haid yang terlalu dini dan status gizi. Tujuan penelitian ini adalah untuk mengetahui hubungan status gizi dan usia menarche dengan kejadian dismenore pada remaja putri di SMAN 2 Bangkinang Kota. Desain yang digunakan survey analitik dengan pendekatan cross sectional. Populasi adalah seluruh remaja putri kelas X dan XI di SMAN 2 Bangkinang Kota. Analisa data yang digunakan yaitu univariat dan bivariat. Terdapat hubungan yang signifikan antara status gizi dengan kejadian dismenore pada remaja putri dengan nilai $p$ value = 0,01 atau $p \leq \alpha(0,05)$, ada hubungan yang signifikan antara usia menarche dengan kejadian dismenore pada remaja putri dengan nilai $p$ value $=0,02$ atau $p \leq \alpha(0,05)$. Oleh karena itu diharapkan pada remaja memperhatikan kebutuhan gizinya dan selalu memantau berat badannya. Status gizi yang baik akan mempengaruhi kejadian dismenore.
\end{abstract}

Kata Kunci : Status Gizi, Umur Menarche, Dismenore

@ Jurnal Ners Prodi Sarjana Keperawatan \& Profesi Ners FIK UP 2021

$\triangle$ Corresponding author :

Address : Jl. Tuanku Tambusai No. 23 Bangkinang

Email : syafrianifani@gmail.com

Phone : 0812-7629-9789 


\section{PENDAHULUAN}

Umur sekolah Menengang Atas (SMA) merupakan periode transisi antara masa kanakkanak ke dewasa. Masa pematangan fisik berjalan kurang lebih selama dua tahun. Biasanya dihitung mulai haid yang pertama pada wanita (Dahro, 2012). Kesehatan reproduksi remaja saat ini masih menjadi masalah yang perlu mendapat perhatian (Dahro, 2012).

Kesehatan reproduksi remaja tidak hanya masalah seksual saja tetapi juga menyangkut segala aspek tentang reproduksi mereka. Pemahaman tentang menstruasi sangat diperlukan untuk dapat mendorong remaja yang mereka alami dan ketidaknyamaan yang dihubungkan dengan yang disebut dismenore (Widyastuti, dkk, 2009).

Dismenore dapat diartikan sebagai rasa nyeri saat menstruasi yang mengganggu aktifitas sehari-hari wanita dan mendorong penderita untuk melakukan pemeriksaan atau konsultasi ke pelayanan kesehatan atau datang ke bidan (Manuaba, 2010).

Dismenore adalah salah satu keluhan yang paling umum pada perempuan muda yang datang ke pelayanan kesehatan atau ke bidan. Rata-rata wanita mengalami rasa tidak nyaman pada saat menstruasi, seperti keram dan biasanya juga dengan mual dan pusing, terkadang pingsan. Dismenore diklasifikasikan menjadi dua jenis, yaitu dismenore primer dan dismenore sekunder (Anugroho, 2011). Dismenore primer adalah nyeri haid yang tidak berhubungan dengan patologi pelvis makroskopis (ketiadaan penyakit pada pelvis). Umumnya terjadi pada tahun-tahun pertama setelah menarche (menstruasi pertama).Dismenore sekunder didefinisikan sebagai nyeri haid sebagai akibat dari anatomi atau patologi pelvis makroskopis, seperti yang dialami oleh perempuan dengan endometriosis atau radang pelvis kronis. Kondisi ini paling sering dialami oleh perempuan berumur $30-45$ tahun (Anugroho, 2011).

Berdasarkan data World Health Organization (WHO) tahun 2017 didapatkan kejadian dismenore sebesar 1.769.425 jiwa $(90 \%)$ wanita yang mengalami dismenore dengan 10-16\% mengalami dismenore berat. Angka kejadian dismenore di dunia sangat besar, rata-rata hampir lebih dari 50\% wanita mangalaminya.

Angka dismenore di Indonesia juga tidak kalah tinggi dibandingkan dengan negara di dunia lainnya. Menurut Proverawati \& Misaroh (2012) di Indonesia angka kejadian dismenore terdiri dari $72,89 \%$ dismenore primer dan $21,11 \%$ dismenore sekunder dan angka kejadian dismenore berkisar $45-95 \%$ di kalangan perempuan umur produktif.

Status gizi merupakan salah satu penyebab kajadian dismenore, status gizi yang mengalami berat badan berlebih merupakan faktor resiko dari dismenore, didapatkan $68,25 \%$ yang dismenore dengan status gizi overweight (Danielle, 2011 dalam Beddu, 2015).

Umur menarche merupakan penyebab timbulnya dismenore, diketahui bahwa kejadian dismenore sebanyak $88 \%$ terjadi pada wanita dengan umur menarche< 12 tahun dibandingkan dengan > 12 tahun sebanyak $65,2 \%$ (Novia, 2008).

Umur menarche yang dini merupakan salah satu faktor terjadinya dismenore, pada dasarnya umur menarche <12 tahun hormon gonadotropin diproduksi sebelum waktunya. Menarche yang terjadi pada umur sebelum waktunya mengalami perubahan dan masih terjadi penyempitan pada leher rahim , maka akan timbul rasa nyeri pada saat haid (Anugroho, 2011).

Terdapat faktor yang mempengaruhi dismenore primer yaitu status gizi. Status gizi dapat dibagi menjadi tiga kelompok : yaitu gizi normal dan gizi kurang kemudian gizi lebih. Remaja dengan status gizi yang kurang selain akan mendapatkan terganggunya fungsi reproduksi. Hal inilah yang berdampak pada gangguan dismenore, akan baik bila asupan nutrisinya baik pula (Nataria, 2011).

Pubertas pada remaja putrid ditandai dengan menstruasi (menarche). Pada permulaan umur menarche, biasanya diikuti haid yang tidak normal. Menarche adalah haid pertama yang biasa terjadi dalam umur 10-16 tahun ditengah masa pubertas sebelum memasuki reproduksi (Sukarni, 2013).

Umur anak perempuan mulai mendapat menstruasi sangatlah bervariasi. Kecenderungan bahwa saat ini anak mendapat 
menstruasi yang pertama kali pada umur muda. Pada saat berumur 12 tahun menstruasi pertama kali, tapi ada juga yang 8 tahun sudah mengalami haid pertama. Umur untuk mencapai fase terjadinya menarche dipengaruhi oleh banyak faktor, antara lain: gizi, sosial, ekonomi, dan lain sebagainya (Sukarni, 2013).

Penelitian oleh Alex, dkk (2017) yang berjudul hubungan status gizi dengan kejadian dismenore pada remaja putri mendapatkan hasil bahwa karakteristik responden yang sebagian besar berada pada kategori umur remaja menengah sebanyak 139 responden $(64,7 \%)$. Remaja putri yang mengalami dismenore intensitas nyeri ringan $(50,7 \%)$. Nyeri sedang $(40 \%)$. Nyeri berat $(9,3 \%)$. Hasil uji statistik didapatkan hasil dengan nilai $\mathrm{p}$ value 0,004 yang berarti ada hubungan antara status gizi dengan kejadian dismenore pada remaja putri di SMA Negeri 8 Pekanbaru.

Hasil penelitian Hasrinta, dkk (2014) yang dilakukan di SMA Negeri 21 Makasar bahwa responden paling banyak umur menarche $<12$ tahun sebanyak $62,0 \%$, dengan nilai $p=0,029$, artinya terdapat hubungan yang signifikan antara umur menarche dengan dismenore primer.

Menurut data Dinas Pendidikan Provinsi Riau ada 3 sekolah di Kabupaten Kampar dengan jumlah siswi terbanyak yaitu SMAN 2Bangkinang Kota, SMAN 1 Bangkinang Kota, dan SMAN 2 Tambang. Dari 3 sekolah terbanyak pertama yaitu SMAN 2 Bangkinang Kota 80, SMA Negeri 1 Bangkinang Kota 76 dan SMAN 2 Tambang 69 orang siswi.

Survey awal yang dilakukan di SMAN 2Bangkinang Kota didapatkan hasil terbanyak yaitu $(37,5 \%)$ yang mengalami dismenore pada saat menstruasi, SMAN 1 Bangkinang Kota didapatkan hasil $(31,25 \%)$ dan di SMAN 2 Tambang didapatkan hasil $(28,75 \%)$ yang mengalami nyeri (disminore) pada saat haid. Berdasarkan data diatas penulis tertarik ingin melakukan penelitian dan mengangkat judul "Hubungan Status Gizi dan Menarche Dengan Dismenore Pada Remaja Putri Di SMAN 2 Bangkinang Kota Tahun 2021.”

\section{METODE PENELITIAN}

Penelitian ini merupakan penelitian survey analitik (survey lapangan) dengan pendekatan "cross sectional" yang bertujuan untuk melihat hubungan antara variabel dependen dan independent. Rancangan cross sectional merupakan rancangan penelitian yang pengukuran atau pengamatannya yang dilakukan secara sekaligus atau sekali waktu. Penelitian ini dilakukan pada siswi di SMAN 2 Bangkinang Kota Tahun 2021.

Penelitian ini dilakukan di SMAN 2 Bangkinang Kota kelas X dan XI pada bulan November tahun 2021. Populasi dalam penelitian ini adalah seluruh siswi kelas X, XI di SMAN 2 Bangkinang Kota Tahun 2021 yang berjumlah populasinya 80 orang. Pengambilan sampel menggunakan teknik total sampling, sampel yang digunakan yaitu seluruh siswi kelas $\mathrm{X}$, XI yang sekolah di SMAN 2Bangkinang Kota sebanyak 80 orang.

\section{HASIL DAN PEMBAHASAN \\ Hasil Penelitian}

Penelitian ini dilakukan selama satu minggu di minggu ke tiga bulan Januari 2021 jumlah responden 80 siswi.

\section{Analisa Univariat}

Analisa univariat dalam penelitian ini yaitu status gizi, umur menarche dan dismenore.

\section{a. Status Gizi}

Tabel 4.1 Distribusi Frekuensi Status Gizi pada Siswi di SMAN 2 Bangkinang Kota Tahun 2021

\begin{tabular}{clcc}
\hline No & Status Gizi & n & $(\boldsymbol{\%})$ \\
\hline $\mathbf{1}$ & Tidak Normal & $\mathbf{5 2}$ & $\mathbf{6 5}$ \\
2 & Normal & 28 & 35 \\
\hline & Total & $\mathbf{8 0}$ & $\mathbf{1 0 0}$ \\
\hline
\end{tabular}

Dari tabel 4.1 bahwa lebih dari separoh besar siswi memiliki status gizi tidak normal yaitu sebanyak 52 orang $(65 \%)$.

\section{b. Umur Menarche}

Tabel 4.2 Distribusi Frekuensi Umur Menarche pada Siswi di SMAN 2 Bangkinang Kota Tahun 2021 
Berdasarkan hasil tabel 4.2 dapat dilihat bahwa siswi mengalami umur menarche terlalu dini sebanyak 44 orang yaitu $(55 \%)$.

\section{c. Dismenore}

Tabel 4.3 Distribusi Frekuensi Dismenore pada Siswi di SMAN 2Bangkinang Kota Tahun 2020

\begin{tabular}{|c|c|c|c|}
\hline No & Dismenore & $\mathbf{N}$ & $(\%)$ \\
\hline 1 & Ya & 47 & 58,8 \\
\hline 2 & Tidak & 33 & 41,3 \\
\hline & Total & 80 & 100 \\
\hline
\end{tabular}

Dari tabel 4.3 dapat dilihat bahwa sebagian besar siswi mengalami dismenore yaitu sebanyak 47 orang $(58,8 \%)$.

\section{Analisa Bivariat}

Hubungan status gizi dan umur menarche dengan kejadian dismenore di SMAN 2 Bangkinang Kota Tahun 2021.

\section{a. Status Gizi}

Tabel 4.4 Hubungan Status Gizi dengan kejadian Dismenore di SMAN 2 Bangkinang Kota Tahun 2021

\begin{tabular}{|c|c|c|c|c|c|c|c|}
\hline \multirow{3}{*}{$\begin{array}{c}\text { Status } \\
\text { Gizi }\end{array}$} & \multicolumn{4}{|c|}{ Dismenore } & \multicolumn{2}{|c|}{ Total } & \multirow[b]{2}{*}{$P$} \\
\hline & \multicolumn{2}{|c|}{ уа } & \multicolumn{2}{|c|}{ tidak } & & & \\
\hline & $\mathrm{N}$ & $\%$ & $\mathrm{~N}$ & $\%$ & $\mathrm{~N}$ & $\%$ & va \\
\hline & & & & & & & \\
\hline Tidak & 3 & 80 & 1 & 42, & 5 & 65 & 0 \\
\hline normal & 8 & ,9 & 4 & 4 & 2 & & 00 \\
\hline \multirow[t]{2}{*}{ Normal } & 9 & 19 & 1 & 57, & 2 & 35 & 1 \\
\hline & & ,1 & 9 & 6 & 8 & & \\
\hline \multirow[t]{2}{*}{ Jumlah } & 4 & 10 & 3 & 100 & 8 & 10 & \\
\hline & 7 & 0 & 3 & & 0 & 0 & \\
\hline
\end{tabular}

Hasil dari tabel 4.4 dapat diketahui bahwa dari 52 siswi (65\%) dengan status gizinya tidak normal, 14 siswi $(42,4 \%)$ dengan tidak mengalami dismenore sedangkan dari 28 siswi (35\%) memiliki status gizi normal, kemudian 9 siswi $(19,1 \%)$ yang dengan dismenore. Berdasarkan uji statistik diperoleh nilai $p=0,001$. Ini berarti ada hubungan status gizi dengan kejadian dismenore di SMAN 2 Bangkinang Kota Tahun 2021

\begin{tabular}{clcc}
\hline No & Umur Menarche & N & $\mathbf{( \% )}$ \\
\hline $\mathbf{1}$ & Dini $(<\mathbf{1 2}$ tahun $)$ & $\mathbf{4 4}$ & $\mathbf{5 5}$ \\
2 & Normal $(\geq 12$ tahun $)$ & 36 & 45 \\
\hline Total & $\mathbf{8 0}$ & $\mathbf{1 0 0}$ \\
\hline
\end{tabular}

\section{b. Umur Menarche}

Tabel 4.5 Hubungan Umur Menarche dengan kejadian Dismenore di SMAN 2 Bangkinang Kota Tahun 2021

\begin{tabular}{|c|c|c|c|c|c|c|c|}
\hline \multirow{3}{*}{$\begin{array}{c}\text { Umur } \\
\text { Menarche }\end{array}$} & \multicolumn{4}{|c|}{ Dismenore } & \multicolumn{2}{|c|}{ Total } & \multirow[b]{2}{*}{$P$} \\
\hline & \multicolumn{2}{|c|}{ ya } & \multicolumn{2}{|c|}{ tidak } & & & \\
\hline & $\mathrm{N}$ & $\%$ & $\mathrm{~N}$ & $\%$ & $\mathrm{~N}$ & $\%$ & va \\
\hline & & & & & & & $\mathrm{e}$ \\
\hline Terlal & 3 & 70 & 1 & 33, & 4 & 55 & 0 , \\
\hline Dini & 3 & ,2 & 1 & 3 & 4 & & 00 \\
\hline \multirow[t]{2}{*}{ Normal } & 1 & 29 & 2 & 66 , & 3 & 45 & 2 \\
\hline & 4 &, 8 & 2 & 7 & 6 & & \\
\hline \multirow[t]{2}{*}{ Jumlah } & 4 & 10 & 3 & 10 & 8 & 10 & \\
\hline & 7 & 0 & 3 & $\mathbf{0}$ & 0 & 0 & \\
\hline
\end{tabular}

Hasil dari tabel 4.5 diketahui bahwa dari 44 siswi (55\%) untuk umur menarche terlalu dini (< 12 tahun), terdapat 11 siswi $(42,4 \%)$ yang tidak dengan dismenore, sedangkan dari 36 siswi (45\%) yang umur menarche normal ( $\geq 12$ tahun), terdapat 14 siswi $(19,1 \%)$ yang dengan dismenore. Berdasarkan uji statistik diperoleh nilai $p=$ 0,002 . Ini berarti ada hubungan umur menarche dengan kejadian dismenore di SMAN 2 Bangkinang Kota Tahun 2021.

\section{SIMPULAN DAN SARAN}

Untuk penelitian mengenai hubungan status gizi dan umur menarche dengan kejadian dismenore pada remaja putri di SMAN 2 Bangkinang Kota Tahun 2021.

\section{SIMPULAN}

1. Lebih dari separoh distribusi frekuensi status gizi tidak normal 
2. Sebagian besar distribusi frekuensi umur menarche tidak normal $<12$ tahun

3. Sebagian besar remaja putri mengalami dismenore pada saat haid

4. Adanya hubungan status gizi dengan kejadian dismenore pada remaja putri di SMAN 2 Bangkinang Kota Tahun 2021.

5. Adanya hubungan umur menarche dengan kejadian dismenore pada remaja putri di SMAN 2 Bangkinang Kota Tahun 2021.

\section{SARAN}

1. Teoritis

Meningkatnya pengetahuan remaja putri tentang status gizi pada dan kesehatan reproduksi serta pengetahuan tentang kejadian dismenore. Melanjutkan penelitian ini dengan meneliti faktor-faktor lain penyebab dismenore dengan desain yang berbeda

2. Praktis

Diharapkan pada remaja putri agar meningkatkan asupan nutrisi, dan mencukupi gizi seimbang, dan istirahat yang cukup, menjaga kondisi agar tidak terlalu lelah. Apabila tidak mampu menyelesaikan sendiri atau keluhan nyeri haid selama menstruasi terus menerus semakin nyeri segeralah konsultasi pada dokter.

\section{DAFTAR PUSTAKA}

Ade, A, (2013) yang dilakukan di SMK YAPSIPA Kota Tasikmalaya Kepmenkes 2010

Almatsier, S, (2008). Prinsip Dasar Gizi. Gramedia Pustaka Utama : Jakarta

Anugroho, (2011). Cara Jitu Mengatasi Nyeri Haid. Yogyakarta : Nuha Medika

Arikunto, Suharsimi, (2010). Produser Penelitian Suatu Pendekatan Praktik. Jakarta : Rineka Cipta

Arisman, (2008). Gizi Dalam Daur Kehidupan. Palembang : EGC

Beddu S, (2015). Hubungan Status Gizi dan Umur Menarche dengan Diemenore Primer pada Remaja Putri. Diperoleh pada tahun 2020

Bobak, (2004). Buku Ajar Keperawatan Maternitas. Edisi 4. Yogyakarta : EGC
Dahro, Ahmad, (2012). Buku Psikologi Kebidanan Analisis Prilaku Wanita Untuk Kesehatan. Salemba Medika : Jakarta

Fauziah, dkk, (2012). Teori Mengukur Nyeri. Edisi Revisi. Yogyakarta : Nuha Medika

Hawari, Dadang, (2008). Manajemen Stress Cemas dan Depresi. Balai Pnerbit FK UI : Jakarta

Hidayat, A, (2010). Metode Penelitian Kebidanan Teknik Analisis Data. Jakarta : Jagakarsa

Judha, M, (2012). Teori Pengukuran Nyeri dan Nyeri Persalinan, Yogyakarta : Nuha Medika

Lubis, (2013). Psikologi Kesehatan Reproduksi Wanita dan Perkembangan Reproduksinya. Jakarta : Kencana

Manuaba, (2010). Reproduksi Wanita. Jakarta: EGC

Nataria. (2011). Faktor-Faktor yang Berhubungan dengan Kejadian Dismenore pada Mahasiswa Fakultas Kedokteran Universitas Pembangunan Nasional "Viteran". Jakarta. Dikutip tanggal 15 September 2020

Notoatmodjo, S, (2012). Metodologi Penelitian Kesehatan. Jakarta : Rineka Cipta

Novia, (2008). Faktor Resiko yang Mempengruhi Kejadian Dismenore Primer. The Indonesian Journal of Public Health, Vol. 4, No. 2, 2008, pp. 96-104

Paath, dkk, (2008). Gizi Dalam Kesehatan Reproduksi. Jakarta : EGC

Pieter, Janiwarti, (2013). Pendidikan Psikologi Untuk Bidan. Yogyakarta : Rapha Publishing

Paramita, (2010). Hubungan Antara Tingkat Kecemasan dengan Dismenore pada Remaja Putri di Pondok Pesantren Imam Syuhodo Polokarto Sukoharjo.http://undip.ac.id. Diperoleh tanggal 26 September 2020

Purwoastuti, Walyani, (2014). Panduan Materi Kesehatan Reproduksi Keluarga Berencana. Yogyakarta: Pustakabarupress

Proverawati, A, (2009). Buku Ajar Gizi untuk Kebidanan. Yogyakarta : Nuha Medika

Proverawati, Misaroh, (2012). Menarche: 
Menstruasi Pertama Penuh Makna.

Yogyakarta: Nuha Medika

Rhamawati, (2012). Dasar-Dasar Kebidanan.

Jakarta : Pustakarya

Khairani, (2015). Hubungan Pengetahuan

Remaja Putri Tentang Dismenore

dengan Penanganan Dismenore di

SMPN 2 Bangkinang Tahun 2015.

Diperoleh 26 September 2020

Sari, (2017). Faktor-faktor yang berhubungan dengan Kejadian Dismenore pada Siswi SMK Swasta Istqlal Deli Tua Tahun 2017. Diperoleh 26 September 2020

Sukarni W, (2013). Buku Ajar Keperawatan Maternitas. Yogyakarta : Nuha Medika

Sulistyoningsih, H. (2011). Gizi Untuk Kesehatan Ibu dan Anak. Yogyakarta : Graha Ilmu

Sulistyawati, Ari. (2009). Buku Ajar Asuhan Kebidanan Pada Ibu Nifas. Jakarta : Salemba medika

Shinta, O.D, dkk. (2014). Faktor- Faktor yang Berhubungan dengan Kejadian Dismenore pada Siswi SMA Negeri 2 Medan Tahun 2014. (KTI) Medan: Fakultas Kesehatan Masyarakat USU Medan

Sofia, dkk. (2013). Faktor-Faktor Yang Berhubungan Dengan Dismenore pada Siswi SMK Negeri 10 Medan Tahun 2013

Supariasa, dkk. (2012). Penilaian Status Gizi. Jakarta : EGC

Sirajuddin \& Saifuddin. (2012). Penuntun Pratikum Penilaian Status Gizi Secara Biokimia dan Antropometri. Makasar : Universitas Hasanuddin

Varney, 2008. (2008). Buku Ajar Asuhan Kebidanan. Jakarta : EGC

Waryana, (2010). Gizi Reproduksi. Yogyakarta : Pustaka Rihama

Widyastuti, dkk. (2009). Kesehatan Reproduksi. Yogyakarta : Fitramaya

Winkjosastro \& Hanifa, (2009). Ilmu Kandungan. Yayasan Bina Pustaka Sarwono Prawirohadjo : Jakarta 